nicht selten ganz farblosen Leptothrix-Form und deren einzelligen Coccen- und Stäbchen-Zoogloea-Formen vor.,1)

Von don einzelligen Zoogloea-Formen des zuletzt genannten leptothrixartigen Jugendzustandes ${ }^{2}$ ) des Plectonema gracillimum interessirte mich insbesondere eine dem Micrococcus thermophilus nob. morphologiseh ganz ähnliche aerophytische $M$.-Form, deren farblose Zellen, nachdem ich das nach Hause gebrachte frische Material in reines Flusswasser legte, schon nach zwei bis drei Stunden, den keimenden Sporen einiger Bacterien ähnlich, ihre ziemlich zarte Membran abstreiften und sich durch Zweitheilung weiter vermehrten.

Neben dieser Micrococeus-Form fand ich an den oben angeführten Orten in einem Vermehrungshause des Prager Vereinsgartens auch eine an der Luft vegetirende Form der Aphanocapsa fuscolutea nob. und zwar in einer der typischen und in einer der A. Nägelii Rich. sich nähernden Form, deren Zellen theils gelblich, theils blass blaugrün gefärbt waren, dann eine ebenfalls aerophytische Form des Ascococcus Billrothii var. thermophilus, deren Zellen und Familien bald farblos, bald blass olivengelb oder rosenroth, meist nackt, seltener von einer gemeinsamen gallertartigen Hülle umgeben, im Gallertlager anderer Spaltpflanzen nistend auftraten. ${ }^{3}$ )

In einem anderen Warmhause sammelte ich an feucbten Wänden eines alten hölzernen Wasserkübels auch eine neue sehr kleine Aphanothece-Form, deren fast oder ganz farblose, meist nur $1 \mu$ dicke, bis dreimal so lange Zellen, welche von ziemlich weiten, gelben bis bräunlichgelben, leicht zerfliessenden Gallerthüllen umgeben waren, formlose Familien im schleimigen. Lager anderer Warmhausalgen bildeten.

\title{
Kleiner Beitrag zur Flora von Hainburg a. d. Donau in Nieder-Oesterreich.
}

\author{
Von H. Braun.
}

Herr Carl Aust, k. k. Bezirksgerichts-Adjunct in Hainburg, übersandte mir behufs Determinirung einige kritische Formen der

1) Man hat in Folge der bisherigen dualistischen Classification der Spaltpflanzenformen einige von diesen fast oder ganz farblosen Warmhaus-Spaltpflanzenformen zu den Spaltalgen, andere (z. B. Bacillus muralis Tomaschek, $\boldsymbol{B}$. lacmus Schröter) zu den Spaltpilzen (Bacterien) zugereiht.

2) Man vergl. Zopf's "Zux Morphologie der Spaltpflanzen“, 1882, p. 45.

3) Dass die an der Luft vegetirende Spaltalge Plectonema gracillimum der im Wasser lebenden Cladothrix dichotoma Cohn in vieler Beziehung ähnlich sich entwickelt, ist bereits von Zopf (l. c. p. 45) hervorgehoben worden. Von demselben Forscher (l. c. p. 4.5 f., p. 53, Ber. d. deutsch. bot. Gesell., I, 7 u. a.), rom Verfasser u. A. ist anch experimentell nachgewiesen worden, dass die an der Luft lebenden Spaltalgen (z. B. Glaucothrix gracillima Zopf, Scytonema foecundum Zopf, Tolypothrix amphibica Zopf, Lyngbya inundata etc.) anch im Wasser zu vegetiren vermögen. 
dortigen Flora angehörend, ein. Sämmtliche dieser Formen wurden im Jahre 1887 gesammelt. Da jeder Beitrag zur Flora von NiederOesterreich sehr wünschenswerth erscheint, dürfte auch nachstehendes Verzeichniss von Standorten einiger kritischer Formen nicht unwillkommen sein.

Mentha mollissima Borkhausen. Fl. der Wetteran II. pag. 348 (1800) M. incana Smith in Rees Cyclop. tom. XXIII sub Mentha Nr. 5 (1819) non Willdenow Enum. plant. hort. Berolin. p. 609 (1809). Von dieser ausgezeichneten Art sind bislang in NiederOesterreich nur wenige Standorte im Thaya-Gebiete bekannt. Prof. Heimerl fand diese Pflanze nächst Eszterház im Oedenburger Comitate Ungarns. In Wassergräben bei Deutsch-Altenburg.

- hirsuta Huds. var. purpurea (Host.). An Wassergräben bei Doutsch-Altenburg.

- ovalifolia Opiz. Naturalien-Tausch p. 70 (1824). In Wassergräben bei Deutsch-Altenburg.

- diffresa Lejeune. Revue de la flore des environs de Spa, pag. 117 (1824). Boreau Fl. de 1. centre de la France III. p. 513. Nr. 1952 (1857). - M. arvensis var. diffusa (Lejeune) Reichenbach Fl. germ. exc. p. $306 \mathrm{Nr} .2077 / 6$ (1832). - M. arvensis g) diffusa (Lejeune) Mutel Flore française III. p. 2 (1836). Icon. Mutel Atlas fig. 349. Reichenb. pl. critic. X. tab. 972 (1832) Reichenb. Icon. fl. germ. XVIII t. 1286. IV. (1858). In einer sumpfigen Grube beim Jägerhause am Gemsenberge nächst Pressburg. Ich fand vor einigen Jahren diese charakteristische Form in grosser Menge in einem ausgetrockneten Sumpfe an der Fischa nächst der Uebersetzung der WienBrucker Eisenbabn.

- arvensis var. divaricata Host Fl. Austr. II. pag. 150 pro specie. (Exemplaria authentica in herb. mus. palat. Vindobon.) Auf Aeckern bei Hundsheim. In Nieder-Oesterreich auf fouchten Brachen und in Kartoffeläckern sehr verbreitet und nach den bisherigen Beobachtungen weit häufiger wie die typische $\boldsymbol{M}$. arvensis L.

Thymus Lövyanus Opiz. An Rainen nächst Wolfsthal in NiederOesterreich, am Schlossberge bei Hainburg.

- Löoyanus var. ellipticus (Opiz) forma gynodynamica. An Wegrändern bei Wolfsthal, am Braunsberge und auf Wiesen nächst Hainburg.

- Lövyanus var. stenophyllus (Opiz). Am Braunsberge bei Hainburg.

- Lövyanus var. bracteatus (Opiz) f. gynodynamica. Am Braunsberge nächst Hainburg.

- lanuginosus Miller (T. Austriacus Bernhardi). Braunsberg nächst Hainburg.

- Kosteleckyanus Opiz. Naturalien-Tausch p. 104 (1824). Am Kirchenberge bei Deutsch-Altenburg, ebendaselbst eine Mittelform zwischen dieser Form und dem T. praecox Opiz. Am Pfaffenberge bei Deutsch-Altenburg. 
Thymus praecox Opiz. Naturalien-Tausch pag. $40(1824)=T$. hamifusus Bernhardi in Reichenbach Flora exc. pag. 312, Nr. 2119 (1832). Gemein am Braunsberge nächst Hainburg.

Rosa canina f. fissidens Borbás. An Wegrändern bei Edelsthal in Ungarn. Im Weidritz-Thale nächst Pressburg.

- canina f. semibiserrata Borbás. Im Weidritz-Thale.

- dumalis Bechstein. Am Pfaffenberge bei Deutsch-Altenburg.

- dumalis var. innocua (Ripart). Am Pfaffenberge nächst DentschAltenburg.

\section{Hienacium Andn'zejowstio n. sp.}

Von Br. Blocki.

Diagnose: Wurzelstock kurz, schief, oberirdische beblättorte, sterile Ausläufer und blühende bogig aufsteigende, reichlich beblätterte Stolonen treibend. Stengel aufrecht, 4-7 Dm. hoch, fein längsgestreift. Blüthenstand doldenrispig (nicht doldig, wio bei den echten Cymosis), ziemlich locker, reichköpfig; aus der Achsel des obersten deckblattartigen Stengelblattes entspringt überdies ein 4-6 Köpfechen tragender, ziomlich langer Ast. Blätter dicklich, steif, lichtgrün. Grundständige Blätter a ufrecht abstehend, lan zettli ch, 1-2 Dm. lang, $1 \cdot 5-2 \mathrm{Cm}$. breit, im oberen Drittel am breitesten, von da zur Basis allmälig verschmälert, stumpflich-spitz (nur die zwei bis drei untersten verkehrteilanzettlich, stumpf), an den Rändern undeutlich entfernt gezähnelt mit weisslichgrünem Mittelnerv. Stengel im unteren Theile zwei- bis dreiblätterig, die Blätter decrescirend, von der Gestalt der Grundblätter, jedoch spitz. Blühendes Köpfchen $6 \mathrm{Mm}$. lang (ohne Ligulae), $4 \mathrm{Mm}$. breit, Ligulae klein, goldgelb. Hüllschuppen schmal lineallanzettlich, etwas über $0.5 \mathrm{Mm}$. breit, stumpflich, häutig berandet, am Rücken schwärzlichgrün. Blätter beiderseits mit Sternhaaren sehr dicht bedeckt; überdies tragen die Blätter beiderseits eine ziemlich dichte Bekleidung, bestehend aus einfachen Haaren, welche an der Lamina sehr kurz (kaum $0.5 \mathrm{Mm}$.) sind und nur auf dem Mittelnerv (unterseits) und an den Blatträndern (gegen die Blattbasis hin) die Länge von $1 \mathrm{Mm}$. erreichen. Der Stengel ist mit Sternhaaren dicht bekleidet und ausserdem mit einfachen kaum $0.5 \mathrm{Mm}$. langen, wagrecht abstehenden Haaren ziemlich spärlich (nur am Grunde dicht) besetzt; gegen den Blüthenstand hin werden am Stengel die einfachen Haare dureh sehr kurze schwärzliche Drüsenbaare fast gänzlich ersetzt, und die daselbst sehr spärlich auftretenden einfachen Haare sind fast zweimal länger als die Drüsenhaare. Die Köpfehenstiele, sowie der Stengel dicht unter dem Blüthenstand sind mit Sternhaaren sehr reichlich bedeckt, daher die Köpfchenstiele fast weiss erscheinen, und aussordem tragen die Köpfchenstiele eine ziemlich. 